СИДОРОВА С. Е. (РЕД.). (2015). ДВИЖЕНИЕ И ПРОСТРАНСТВО: ПАРАДИГМА МОБИЛЬНОСТИ И ПОИСКИ СМЫСЛОВ ЗА ПРЕДЕЛАМИ СТАТИЧНОСТИ. МОСКВА: ВОСТОЧНАЯ ЛИТЕРАТУРА. 911 С. (ПОД НЕБОМ ЮЖНОЙ АЗИИ). ІSBN 978-5-02-036603-9

\author{
Константин Глазков \\ Аспирант департамента социологии, преподаватель \\ кафедры методов сбора и анализа социологической информации \\ Национального исследовательского университета «Высшая школа экономики» \\ Адрес: ул. Мясницкая, д. 20, г. Москва, Российская Федерация 101000 \\ E-mail: glazkov.konst@gmail.com
}

Рецензируемая работа является результатом многолетнего междисциплинарного проекта по изучению территориального конструкта под названием «Южная Азия». Пожалуй, во всей серии опубликованных и планируемых для публикации книг том «Движение и пространство» выглядит самым фундаментальным. Такое название вкупе с суровой толщиной сборника способно отпугнуть иного робкого читателя. И напрасно. Это очень увлекательное чтение! Книга состоит из разнообразных статей и двух важных введений, одно из которых поясняет нам происхождение «Южной Азии» и проекта (И. Глушкова), другое раскрывает общий концептуальный подход («мобильный поворот»), который объединяет весь сборник (С. Сидорова). Основной корпус материалов делится на пять важных с культурноисторической точки зрения сюжетов в формировании южноазиатской действительности («Путь на родину», «Бегство на чужбину», «Власть на выезде», «Символы на марше», «В поисках выгоды»), а также на три модальности переживания мобильности («По шоссе», «По рельсам», «По воде»). Из них, в частности, мы можем узнать, что:

- население в регионе по большому счёту состоит из «мигрантов», «завоевателей» и «чужаков», где каждый архетип получает этническое наполнение лишь в отношении к тому контексту, в который он погружен (А. Сафронова, Е. Ванина);

- «самые страшные случаи насилия бывают там, где встречаются друг с другом колонны беженцев» (Л. Чернышева, с. 151);

- многие могольские падишахи отсутствовали в официальной столице большую часть своего правления, например, Аурангзеб 34 года из 49 лет правления (69\%), а его сын Бахадур-шах I «находился в пути все 5 лет своего правления» (Е. Ванина, с. 209);

- в XVII веке редко удавалось увидеть одновременно хвост и голову каравана, в состав которого входило в среднем 100-20о повозок (Е. Ванина, с. 407);

- в Индии есть знак «Запрет на движение слонов» (фотовставка «Регуляторы движения», с. 544-545).

(ㄷ) Глазков К. П., 2017

(ㄱ Центр фундаментальной социологии, 2017

DOI: $10.17323 / 1728-192 \mathrm{X}-2017-3-436-439$ 
Помноженные на численность населения и запутанный культурный контекст, любой из упомянутых процессов или явлений обретает колоссальный эффект и поражает сознание. Впечатления от прочитанного усиливаются также за счет приведенных как бы между делом переводных художественных произведений и исторических документов.

Удачные находки приведенными выше фактами не ограничиваются. В книге авторы порой находчиво нащупывают различные сцепки между аспектами мобильности и другими, казалось бы, далекими от неё процессами. Среди них особенно хочется выделить несколько пассажей, посвященных необходимости для правителей разных эпох совершать перемещения по стране. «Вместе с падишахом по его владениям перемещалась сама власть, ее надлежало демонстрировать подданным, соседям и потенциальным мятежникам во всей мощи и блеске. Палаточный «городок», в котором располагался монарх, воспроизводил устройство императорской резиденции, и даже сами шатры носили названия соответствующих дворцов... - вместе с шатрами все это создавало подвижную копию столицы» (И. Глушкова, с. 217).

И еще два небольших фрагмента.

«Каждое письмо... уточняет его [монарха] местонахождение и дальнейшее направление следования и изобилует глаголами движения («уйти», «прийти», «выступить», «тронуться», «пересечь» и т. д.)...» (И. Глушкова, с. 223).

«Новость с языка» стоила меньше, чем «бумажная новость/новость с пера», а к известиям от ростовщиков/купцов/торговцев относились с вниманием, как и к брахманским, поскольку и те и другие передвигались на большие расстояния» (И. Глушкова, с. 226).

Первый фрагмент прекрасно передает идею, что поддержание власти во времена Империи Великих Моголов требовало постоянного курсирования собственно самой власти, которая была вынуждена поддерживать свою модель на ходу, воспроизводя все властные отношения каждый раз на новом месте. Второй фрагмент, акцентирующий внимание на важности глаголов движения в переписке, очень напоминает современные исследования мобильности, когда в фокусе анализа оказывается переживание разных типов мобильности, а также осуществляется поиск категорий для его описания ${ }^{1}$. Третий фрагмент иллюстрирует интересную взаимосвязь между «достоверностью» информации и подвижностью ее источника.

Концептуальная оптика позволяет разглядеть в исторических фактах источник для теоретического размышления. Однако в сборнике редко встречаются развернутые теоретические рассуждения. Чаще изложение материала заканчивается любопытным, но сравнительно кратким суждением.

1. Например, см.: Pascoe D. (2001). Airspaces. London: Reaktion; Rosler M. (1998). In the Place of the Public // Rosler M. In the Place of the Public: Observations of a Frequent Flyer. Ostfildern-Ruit: Cantz. P. 2679; Thackera J. (1997). Lost in Space: A Traveller's Tale // Bode S., Millar J. (eds.). Airport. London: The Photographers' Gallery. P. 58-69; Williamson T. (2003). The Fluid State: Malaysia's National Expressway // Space and Culture. Vol. 6. № 2. P. 110-131; Wollen P., Kerr J. (eds.). (2002). Autopia: Cars and Culture. London: Reaktion. 
В этом плане особняком стоит статья Д. Мэсселоса «По городским артериям: мобильные формы протеста», которая начинается с проблематизации соотношения пути и пространства («путь - это стрела сквозь пространство», с. 336) и заканчивается некоторыми соображениями относительно того, как представленные случаи из концепции Сатъяграха «высвечивают различия между тем, как дорога или маршрут функционируют, и тем, как они воспринимаются» (с. 353). Отличительная особенность данной статьи заключается в том, что в ней сохраняется баланс между теоретическими проблемами и историческими материалами, когда детальное освещение устройства протестных маршрутов работает на раскрытие связи движения и его репрезентаций.

Критически отнестись ко всем статьям автор рецензии не решается ввиду недостаточной эрудиции. Эта книга - очень специальный труд, который по достоинству могут оценить лишь узкие специалисты. Тем не менее здесь есть важный аспект, который заслуживает отдельного социологического рассмотрения. Во введении С. Сидоровой указано, что основным концептуальным каркасом книги, общим для всех авторов, стал так называемый «мобильный поворот». Парадигма «новых мобильностей» известна и широко признана в мире. Обзор теорий, развиваемых в русле «мобильного поворота», проделан в книге превосходно. Создается ощущение, что были упомянуты многие, если не все ключевые имена. Затронуты, в частности, тексты Баумана, Урри, Кастельса, Крессвелла, Мэсси, Оже, Рел$ф a$, Харви, Шеллер. Дан также краткий анализ рецепции «мобильного поворота» в разных дисциплинах (географии, социологии, антропологии, истории), хотя некоторые дисциплинарные границы кажутся здесь довольно условными.

В этом обзоре есть одно очень важное высказывание, к которому рецензент хотел бы привлечь внимание. Есть разница между исследованиями, где мобильность выступала лишь как тема, и такими исследованиями, где она формулируется как проблема. А это значит, что описания мест, между которыми совершаются перемещения, не обязательно предполагают включение в парадигму мобильности. «Несмотря на то, что теория увязывалась с мобильностью, на самом деле она была о местах» (С. Сидорова, с. 29). В связи с этим замечанием и возникает главный читательский вопрос. Действительно ли это сборник работ, выполненных в рамках «мобильного поворота», или авторы попросту ${ }^{2}$ обращаются к теме движения с разных сторон?

Иногда возникают сомнения по поводу полной преемственности между «насаждаемой» теорией и изложенным материалом. В некоторых местах эта рассогласованность приводит, как нам кажется, к некоторым нарушениям концептуальной целостности, связности между так называемым «мобильным поворотом» и сложившимися за его пределами теориями интерпретации типов культур. Например, в книге говорится о магистральном и локальном типах культур ${ }^{3}$ для пояснения

\footnotetext{
2. Хотя это совершенно неуместное слово по отношению к собранному материалу.

3. Головнев А. В. (2009). Антропология движения (древности Северной Евразии). Екатеринбург: Волот.
} 
того, в каких отношениях находились Британская империя и властители Индостана (С. Сидорова, с. 235). Как это связано с мобильностью? «Применительно к британской магистральной культуре идея движения как механизма доминирования воплотилась в равномерной дисперсии власти по территории Индостана через опутывание его бюрократической сетью...» (с. 251). Нам кажется, что это нуждается в дополнительных обоснованиях, без которых выглядит как натяжка. Понятно, что теория типов культур, основывающаяся на методике анализа «мотивационнодеятельностных схем и историко-антропологических сценариев», имеет довольно опосредованные связи с теми подходами, которые получили развитие в западной традиции вместе со своим условным названием.

Сомнения в некоторых случаях усиливаются ввиду соотношения теоретических и собственно исторических источников, приводимых в конце каждой главы. Очевидно, что преобладают исторические источники и акценты делаются на «мобильных» аспектах истории Южной Азии, а не на проблематизации того, что считать «мобильным». Однако мы отдаем себе отчет в том, что перед нами - лишь один из первых опытов такого рода.

Подводя итог, важно отметить, что обсуждаемый сборник в первую очередь вносит существенный вклад в изучение и систематизацию материалов, связанных с Южной Азией и раскрывающих ее с «мобильной» стороны, а потому настоятельно рекомендуется к прочтению. Оптика «мобильного поворота» делает рассказанные истории в высшей степени занимательными и привлекательными. Иногда совсем не важно, какое отношение все это имеет к пресловутому повороту. Особенно когда истории приправлены поэзией Ниссима Эзекила («Утренняя прогулка») и Редьярда Киплинга («Сухопутная почта»).

\section{Book Review: Svetlana Sidorova (ed.). Dvizhenie i prostranstvo: paradigma mobil'nosti i poiski smyslov za predelami statichnosti [Mobility and Space: In Quest of Meanings Beyond Stasis] (Moscow: Vostochnaya literatura, 2015)}

\section{Konstantin Glazkov}

Graduate Student, Lecturer, Department of Sociology, National Research Unversity Higher School of Economics Address: Myasnitskaya str., 20, Moscow, Russian Federation 101000

E-mail: glazkov.konst@gmail.com 